\title{
Reducing Turbulences in Industrial Supply Chains
}

\author{
Stanisław Strzelczak \\ Warsaw University of Technology, Faculty of Production Engineering, \\ Narbutta 85, 02-524 Warsaw, Poland
}

\begin{abstract}
Turbulent behavior of supply chains is drawing an increasing attention of researchers and managers in recent years. Better understanding of reasons and impacts of unsteadiness is interesting not only from the scientific point of view, but also crucial for the development of appropriate practical countermeasures. Many publications focus the bullwhip effect. Few consider other symptoms of turbulent behavior, than oscillations of material flows and stocks in supply chains or volatility of the demand. This paper takes a holistic perspective at turbulences in industrial supply chains, in terms of symptoms, effects and interdependencies. A relevant analytical framework is discussed, which employs both, qualitative and quantitative modeling. Initial results of empirical and conceptual research are presented. The final aim is to develop a well-justified methodology for simultaneous analysis of cultural phenomena and material processes. The two major streamlines of processes in supply chains were considered, i.e.: product development and production flow. The obtained and prospective results have both, scientific and practical importance.
\end{abstract}

\section{Introduction}

A typical global supply chain is a complex and spatially spread structure of collaborations, with many parallel cross-organizational business processes going on, including flows of materials, engineering, information, decisions, cash and finance, legal responsibilities, innovations etc. All of them go on simultaneously with social processes, i.e. interactions of organizations, groups and individuals. Not surprisingly, the high level of complexity, enhanced by the global dimension of business, easily results in unpredictable and turbulent behaviors of supply chains, reflected by both, the material and cultural phenomena. Turbulences, variances, oscillations, disturbances, disruptions, risks, perils, conflicts, tensions are just the few names, which are used to describe symptoms of volatility, vulnerability, unstableness, unpredictability and disharmony in supply chains. The opposite behavior can be named as steady, smooth, undisturbed, reliable, predictable, resilient or robust.

Please use the following format when citing this chapter:

Strzelczak, S., 2008, in IFIP International Federation for Information Processing, Volume 257, Lean Business Systems and Beyond, Tomasz Koch, ed.; (Boston: Springer), pp. 393-402. 
The turbulent behavior of supply chains is usually referred to industrial and business dynamics $[1,2]$ or the bullwhip effect $[3,4]$, i.e. the phenomenon, where a demand flowing upstream of a supply chain exhibits a greater variance, than that its end. The bullwhip effect has been observed in many industries, often resulting in excessive inventories, inadequate schedules, overproduction, poor customer service, tremendous inefficiencies, lost revenues and increased costs. Table 1 resumes factors usually linked to the bullwhip effect, and the typical suggested countermeasures [5]. Other suggested factors are: distortion in communication up and down supply chains, weak coordination - local decisions, long and variable lead times, delayed material and information flows, neglecting to order in an attempt to reduce stocks, overreaction to backlogs, inappropriate incentives and performance measures, free return policies. It is striking that the $3 \mathrm{Mu}$ concept of Toyotism (e.g. Muri means: unevenness, irregularity, variability), which extends directly to supply chains, is almost never discussed in this context, despite well-known practices of Toyota [6].

Table 1. The bullwhip effect and suggested countermeasures

\begin{tabular}{|c|c|}
\hline Factor & Remedy \\
\hline $\begin{array}{l}\text { Order batching -occurs in an } \\
\text { effort to reduce ordering costs, } \\
\text { to take advantage of } \\
\text { transportation economics (e.g. } \\
\text { full truck load). }\end{array}$ & $\begin{array}{l}\text { High order costs are countered with ICT: Electronic Data } \\
\text { Interchange (EDI) and computer-aided ordering. Full truck } \\
\text { loads are countered with third-party logistics and assorted } \\
\text { truck loads. Random or correlated ordering is countered with } \\
\text { regular delivery appointment. More frequent ordering result in } \\
\text { smaller orders and smaller variance (the reduction is seen } \\
\text { upstream, not locally; the required safety stock may increase } \\
\text { or decrease depending on circumstances). }\end{array}$ \\
\hline $\begin{array}{l}\text { Demand forecasting } \\
\text { inaccuracies: certain percents } \\
\text { are added to the demand } \\
\text { estimates upstream supply } \\
\text { chain, resulting is no visibility } \\
\text { in the true demand. }\end{array}$ & $\begin{array}{l}\text { Replace the forecast-driven management and inventory } \\
\text { replenishment by the demand-driven management (pull-flow). } \\
\text { Collaborative forecasting, single control of replenishment or } \\
\text { Vendor Managed Inventory (VMI) can overcome exaggerated } \\
\text { demand forecasts. Poor demand visibility can be addressed by } \\
\text { ICT, e.g. direct access to point of sale (POS) data. Long lead } \\
\text { times should be reduced, where economically advantageous. }\end{array}$ \\
\hline $\begin{array}{l}\text { Inflated orders: rationing and } \\
\text { shortage gaming during } \\
\text { periods of short supply, due to } \\
\text { the hope that possible partial } \\
\text { shipments will be sufficient. }\end{array}$ & $\begin{array}{l}\text { Proportional rationing schemes are countered by allocating } \\
\text { unit based on past sales. Ignorance of supply chain conditions } \\
\text { can be addressed by partnership: sharing capacity and supply } \\
\text { information. Unrestricted ordering capability can be addressed } \\
\text { by reducing the order size flexibility and capacity reservations } \\
\text { (e.g. a fixed quantity for a given year; a quantity of each order } \\
\text { is specified shortly before it is needed, assuming the sum of } \\
\text { the order quantities does not exceed the reserved quantity). }\end{array}$ \\
\hline $\begin{array}{l}\text { Price fluctuations: sales } \\
\text { incentives, trade and retail } \\
\text { level promotions, discounts. }\end{array}$ & $\begin{array}{l}\text { Minimize incentives. High-low pricing can be also replaced } \\
\text { with every day low prices (EDLP). Special purchase contracts } \\
\text { can be implemented in order to specify ordering at regular } \\
\text { intervals to better synchronize delivery and purchase. }\end{array}$ \\
\hline
\end{tabular}




\section{Existing Research}

The primary issue of researching the bullwhip effect is its measurement. Fransoo and Wouters [7] discussed conceptual and practical aspects: incompleteness of data, aggregation of data, isolation of demand data for a defined chain, that is a part of a greater one. Kawagoe and Wada [8] tried to quantitatively define the bullwhip effect and discovered, that a frequency based statistical measure, such as stochastic dominance, is not appropriate to capture the bullwhip effect quantitatively, as it cannot distinguish between a case of the bullwhip effect and a counterexample. But the descriptive statistics (mean and standard deviation) work well.

The next stream of research focuses reasons of the bullwhip effect and their impacts. Kahn [9] showed that serially correlated demands ehnhance the bullwhip effect. Lee et al. [3, 4] used the same demand assumption, and a cost minimization approach to show, that a distortion in demand arises, when retailers optimize orders, and that amplification increases, as the replenishment lead-times increase. Dejonckheere et al. [10] used the control theory to evaluate the bullwhip effect. Chen et al. [11] proved that exponential smoothing forecasts by the retailer can cause the bullwhip effect, and contrasted this with the increase in variability due to the use of moving average forecasts. They considered a correlated demand process, and another one, with a linear trend. Disney et al. focused on smoothing replenishment rules that are able to reduce the bullwhip effect across a single echelon [12]. They quantified the variance of the net stock and computed the required safety stock as a function of the smoothing required. The analysis showed, that bullwhip effect can be satisfactorily managed without unduly increasing stock levels to maintain target fill rates. Moyaux et al. [13] showed by agent-based simulations, that speculation reduces price fluctuation. Papangnou et al. [14] proposed a state-space approach to analyze the simple series supply chain model with an arbitrary number of nodes and developed techniques to calculate explicitly the associated covariance matrix in parametric form, under white-noise demand profile assumption. This allows to check the effect of a parameter-set in the studied inventory policies on the bullwhip effect.

Another way to research the bullwhip effect is by modelling. Warburton presented fundamental differential delay equations to describe how the order variability increases as orders propagate along the supply chain [15]. The analytical solutions are consistent with numerical integrations and previous control theory results. Lu et al. investigated the complexity of the bullwhip effect as a phenomena, using theories of fractals and chaos [16]. They demonstrated that the bullwhip effect and the butterfly effect share the same nonlinear mechanism of amplifying selfoscillations (the ordering decisions amplify perturbations brought by errors, in the processing of demand information). Helbing and Lämmer [17] investigated stability and dynamic behavior of supply networks for different topologies, including: sequential supply chains, "supply circles", "supply ladders" and "supply hierarchies". They applied network theory models to optimize the supply chains. Makajić-Nikolić et. al. studied Petri nets' capability for modeling supply chains and developed a simple three-stage supply chain with one player at each stage: a retailer, a wholesaler and a manufacturer [18]. They used a timed hierarchical coloured Petri Net. The results were similar to those obtained through the beer game. 
Carlsson and Fullér [19] used fuzzy sets theory to show, that if the members of the supply chain share information and agree on continuously improving fuzzy estimates (as the time advances) of future sales, then the bullwhip effect can be significantly reduced. Dhahri and Chabchoub [20] proposed a non-linear goal programming models to quantify the bullwhip effect in supply chain. They used preference functions, based on a statistical chronological series analysis, in order to describe: the demand, the stock level, and the order quantity.

Kelepouris et. al. used the simulation to explain how specific replenishment parameters affect: order variability amplification, product fill rates and inventory levels, across the supply chain [21]. They also studied, how demand information sharing can help reducing order oscillations and inventory levels, in upper nodes of a supply chain. A two-stage supply chain consisting of a warehouse and stores was modeled. A real demand data was used. Jakšic and Rusjan also examined the influence of different replenishment policies on the bullwhip effect [22]. Their paper demonstrates, that certain replenishment policies can in themselves be inducers of the bullwhip effect, while others inherently lower the demand variability. The main causes of increase in variability are projections of future demand expectations, which result in over-exaggerated responses to changes in demand. The authors suggest that, through appropriate selection and use of certain replenishment rules the bullwhip effect can be avoided, thus subsequently allowing supply chain management costs to be lowered. Merkuryev et al. [23] evaluated the impact of decentralized and centralized information sharing strategies combined with two inventory control policies: min-max and stock-to-demand, for a four-stage supply chain (retailer, wholesaler, distributor and manufacturer), using simulation models developed by the Arena 5.0 software package. The models with centralized information structures appeared to be superior in terms of the bullwhip effect, while stock-to-demand inventory control presented better performance than the Min-Max. No cost considerations were taken into account. Finally, Thun and Mertens [24] applied systems dynamics to research the impact of alternative reverse logistics modes on the bullwhip effect, in a closed-loop supply chain environment. Product returns can aggravate the bullwhip effect, but by planning the reverse logistics, the negative influences of the bullwhip effect can be mitigated.

Another stream of publications on the bullwhip effects presents results of the empirical research. Donohue and Croson [25] reported results of experimental studies on the behavioral causes of the bullwhip effect: decision-makers continue to exhibit the bullwhip effect even under conditions where it rationally should not occur. This suggests that cognitive limitations contribute to the bullwhip effect, even in ideal and controlled settings like the lab. Transmitting dynamic inventory information lessens the bullwhip effect, particularly at higher echelon levels. In another paper [26] the same authors used again a controlled version of the beer distribution game, as the setting for the experiment, and varied the amount and location of inventory information shared. First, they independently tested whether sharing upstream or downstream inventory information helps reduce the bullwhip behavior, and found that only downstream information sharing leads to significantly lower order oscillations throughout the supply chain. They compared the reduction in order oscillations experienced by supply chain level and found, that upstream supply chain members benefit the most from sharing downstream information. 
$\mathrm{Wu}$ and Katok [27] also used the beer game, communication protocols and manipulated training. They found that order variability decreases significantly in a setting, in which participants start with hands-on experience, and are then allowed to formulate team strategies collaboratively. This result indicates, that while training may improve individuals' knowledge and understanding of the system, it does not improve supply chain performance, unless supply chain partners are allowed to communicate and share this knowledge. Their results also confirms that the bullwhip effect is enhanced by an insufficient coordination in a supply chain. Lurie and Swaminatham [28] examined behaviorally a two-stage supply chain: manufacturer and retailer; the manufacturer incuring setup costs and following a two point inventory (s, S) policy). They tried to explain, how information about the retailer's ordering policy and consumer demand, and performance-based incentives affect manufacturer decision making behavior. It has appeared that with or without incentives, having greater information from the retailer, improves manufacturer performance consistent with normative predictions. But they did not find any evidence for diminishing returns from information, when incentives are present.

Nienhaus et al. [29] performed a simulation research, based on the use of the beer distribution game online. It is one of the few publications, which discuss impacts of human behavior, as partner in a supply chain, on the bullwhip effect, comparing to simple agent-based strategies. The analysis proved that human behavior need to be recognized as a further factor of amplification of the bullwhip effect, as humans actually act like obstacles to the information flow in supply chains. Sterman [2] also tried to model the human behavior and proposed simulation means to analyze the cognitive process of formation and evolution of expectations of decision makers. He explained the instability and oscillations in industrial supply chains by behavior of forecasters, who systematically underestimate the growth rate of inputs. Ruël et al. [30] explicitly related personality characteristics to the supply chain performance, within experimental context of the beer game. They have shown, that differences in personality characteristics such as: risk taking, efficacy, ambiguity, and locus of control, lead to differences in performance. Low risk taking persons increase on average back order costs and lower inventory costs, while high risk taking persons are supposed to show an opposite impact on the cost structure.

The recently published book, edited by Carranza Torres and Villegas Morán [31], presents a wide overview of industrial dynamics applications to the bullwhip effect. Systemic, endogenic and structural causes of the bullwhip effect were subject of a detailed discussion. E.g. parameters like: normal inventory coverage, manufacturing cycle lead time (acquisition delay for inventories), inventory adjustment time, WIP adjustment time, time to average order rate, have strong impact on oscillations, amplifications, attenuations and phase lags of production and inventories. Following these considerations, four paradigms to mitigate and control the bullwhip effect were suggested: echelon elimination (structural complexity reduction), information transparency, time-compression, and control system.

From other publications we can derive importance of other paradigms: variety reduction (of items), variance reduction (or reliability improvement), postponement, taming constraints (bottlenecks), alignment / partnering, learning, and recently risk management and vulnerability [32]. Finally, the concepts of flexibility, adaptability, agility, sustainability, and resilience [33] are also referred to the considered problem. 


\section{Research Framework}

The existing research on turbulent behavior of supply chains, depending on the purpose and related paradigms, typically follows the spirit of research and takes one of the two following perspectives rooted in the systems theory:

1. Process perspective: supply chain is viewed by a structure, usually network, of processes, sub-processes and operations.

2. Interdependencies perspective: supply chain is viewed as a structure of interacting organizations, resources, infrastructure and environment.

Consecutively, industrial dynamics and mathematical modeling are exploited to study quantitative dynamic phenomena, while the beer game and questionnaire reviews dominated the streamline of research, which focus behavioral phenomena. Exceptionally the risk management takes another perspective of reality and considers unlikely events as atomic entities, with attributed possibilities and severities.

The operation and behaviors of supply chains can be considered at different levels of abstraction or hierarchy, and at different time perspectives: from events to long-term phenomena, that can be described by quantitative measures (e.g. "growth of variance of ...") or in a qualitative way (e.g. as "increasing mistrust"). Causal relations are crucial to understand and analyze the qualitative and quantitative phenomena, especially simultaneously, e.g. by trade-offs. This sets an issue and demand for hybrid analysis and modeling, including the means to model dynamic qualitative phenomena. Explaining causal relations empirically, or by statistical or mathematical modeling, is often risky, and sometimes not possible at all. Beliefs (of experts) are often the only (if any) available arguments to draw conclusions or verify alternative hypothesis. To meet the assumed objectives and to be consistent with the reality, the obstacle of data gathering and aggregation has also to be overcame.

Table 2. The research framework for hybrid analysis of turbulent behavior in supply chains

\begin{tabular}{|l|l|}
\hline \multicolumn{1}{|c|}{ Stage } & \multicolumn{1}{c|}{ Means } \\
\hline Identification & Semi-structured questionnaires \\
\hline Mapping & $\begin{array}{l}\text { Development of process, structural and influence diagrams, } \\
\text { causal networks by structured interviewing and questionnaires }\end{array}$ \\
\hline $\begin{array}{l}\text { Assessment (of likelihoods, } \\
\text { impacts etc.; setting metrics) }\end{array}$ & $\begin{array}{l}\text { Expert assessment (Delphi etc.) + Statistical analysis of beliefs } \\
\text { (Pearson - correlations; Cronbach's Alpha - reliability) }\end{array}$ \\
\hline Modeling & $\begin{array}{l}\text { Scenarios + system dynamics (iThink) + Bayesian Belief } \\
\text { Networks (MSBNx + Hugin Lite) }\end{array}$ \\
\hline Dynamic and causal analysis & $\begin{array}{l}\text { Scenarios + management games + hybrid simulations } \\
\text { (prototype hybrid of BBN and system dynamics) }\end{array}$ \\
\hline Cognitive assessment & $\begin{array}{l}\text { Case studies, statistical analysis (Pearson - correlations; } \\
\text { Cronbach's Alpha - reliability); cognitive action learning }\end{array}$ \\
\hline
\end{tabular}

Following these considerations a research framework has been developed. It is presented in a structured way in the table 2, reflecting the sequence of research steps. Principally diagrams are used to model the reality and phenomena (example: Fig.1). They are graphs: nodes represent variables and functions (influence, evidence etc.). 
Two types of variables are possible: chance (likelihood, probability) and control (decision): one variable represents an exhaustive set of mutually exclusive events, i.e. the domain (states, levels, values, choices, options etc.; discrete or continuous). For each variable a set of likelihood or probability distributions, conditional on some variables, may be specified. Links represent relations among variables and influence functions - properties of (conditional) interdependences among variables. Influence diagrams may be applied as sequential scenarios. For a set of discrete evidence variables the evidence appears in the form of a likelihood distribution over the possible states (an evidence function or potential). A key inference task is to compute posterior probabilities, depending on the general evidence received from external sources (nodes) about the possible states/values of a subset of the variables of the network. A hybrid algebra, mixing computations (events perspective) and causal influences (conditional reasoning) drives simulations. Hierarchical networks allow work at different levels of abstraction, as well as exploit the encapsulation and inheritance concepts known from the object-oriented paradigm. Diagrams may reflect empirical results, then eventually becoming inputs to simulations.

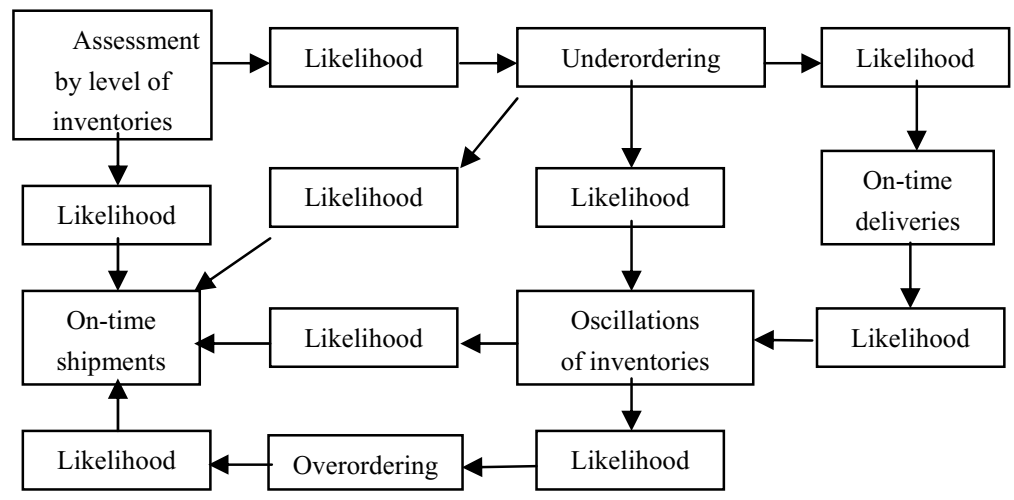

Fig. 1. An example causal diagram of supply chain qualitative and quantitative dynamics

\section{Scope of the Research and the Key Findings}

The research was primarily oriented to develop a well-justified methodology, that could holistically integrate qualitative and quantitative analysis and modeling of those phenomena in supply chains, that result in a turbulent behavior. Operational processes and engineering (product development) were focused. The scope of research, due to its pilot nature, was reduced to ordering and stock management policies (system dynamics), confronted with systemic solutions (performance measures, employees' assessment schemes and incentives) and behavioral qualities (trust, partnership vs. adversarial attitudes).

The empirical research was run in 44 companies (including collaborating MNEs and SMEs), operating in Central Europe, China and Japan. The first steps of the research and the inputs to the dynamic modeling were run according the framework set in the table1. Qualitative assessments were typically based on pre-defined multiperspective and modular patterns (of behavior) and simple grading scales. Hybrid 
simulations were supported by management games. Several important findings, both of scientific and practical importance, were obtained, including the following:

- The impact of turbulences on supply chains performance (including the role of aligned forecasting, planning, scheduling and replenishment) is highly underestimated by practitioners; relevant reporting and modeling practices could help much to realize and understand the phenomena.

- Some factors of behavioral and non-behavioral nature, seems to play a crucial role in most practical situations, e.g. trust, attitudes toward other parties, key performance measures, which may have both, positive and negative impacts.

- Holistic consideration of material phenomena together with behaviors and cultural phenomena is crucial to avoid surprising turbulences and inefficiencies.

- Dynamic modeling of managerial and material processes by means of hybrid simulation is possible and is useful to explain the dynamics of supply chains.

- Cultures and systemic solutions can be leveraged and harmonized. In the context of global supply chains, they may be aligned, by applying the concepts and methods of business integration engineering [6].

\section{Conclusions}

The obtained results advocate, that the research efforts, concerning hybrid analysis and modeling of supply chains, should be continued. The theoretical perspective includes: further structuring of concepts, development of truly holistic and complete research methodology (including the modeling tools and hybrid simulations) and possibly new frameworks for supply chain redesign and reengineering. Concerning empirical continuation, a more wide and extensive inductive $\&$ cognitive research is needed, supported by more relevant statistical evidence. Practice oriented developments should target improvement tool-kits, educational materials (e.g. management games), and recommendations, like benchmarks and maturity models.

\section{References}

1. J.W. Forrester, Industrial Dynamics. A major breakthrough for decision makers, Harvard Business Review, Vol. 36 (1958) No. 4, pp. 37-66.

2. J.D.Sterman, Business Dynamics, McGraw-Hill, 2000.

3. H.L. Lee, V. Padmanabhan, S. Whang, The bullwhip effect in supply chains, Sloan Management Review, Vol. 38 (1997), No. 3, pp. 93-102.

4. L.H. Lee, V. Padmanabhan, S. Whang, Information distortion in a supply chain: The bullwhip effect, Management Science, Vol. 43 (1997) No. 4, pp. 546-558.

5. P.-P. Dornier, R. Ernst, M. Fender, P. Kouvelis, Global Operations and Logistics, John Wiley \& Sons, 1998, pp. 216-233.

6. S. Strzelczak, Business Integration Engineering, in: edited by S.Strzelczak, Economic and Managerial Developments in Asia and Europe - Comparative Studies, Kramist Ltd., 
2003, pp. 99-118.

7. J.C.Fransoo, M.J.F. Wouters, Measuring the bullwhip effect in the supply chain, Supply Chain Management: An International Journal, Vol.5 (2000), No,2, pp. 78-89.

8. T. Kawagoe, S. Wada, The bullwhip effect: a counterexample, Proceedings of the IEEE International Conference on Intelligent Agent Technology, 2005, pp. 124- 127.

9. J. Kahn, Inventories and the volatility of production, American Economic Review Vol. 77 (1987), No. 4, pp. 667-679.

10. J. Dejonckheere, S.M., Disney, M.R. Lambrecht, D.R. Towill, Measuring and avoiding the bullwhip effect: A control theoretic approach, European Journal of Operational Research, Vol. 147 (2003), No. 3, pp. 567-590.

11. F. Chen et al., The impact of exponential smoothing forecasts on the bullwhip effect, Naval Research Logistics Vol. 47 (2000), No.4, pp. 269-286.

12. S.M. Disney, I. Farasyn, M.R. Lambrecht, D.R. Towill, W. van de Velde, Dampening variability by using smoothing replenishment rules, DTEW Research Report 0502, Katholieke Universiteit Leuven, 2005.

13. T. Moyaux, P. McBurney, Reduction of the Bullwhip Effect in Supply Chains through Speculation, in: Ch.Bruun (ed.), Advances in Artificial Economics - The Economy as a Complex Dynamic System, Springer, 2006, p. 77-89.

14. C. Papanagnou, G. Halikias, A State-Space Approach for Analyzing the Bullwhip Effect in Supply Chains, Proceedings of ICTA'05, London 2005, pp. 79-84.

15. R.D.H. Warburton, An Analytical Investigation of the Bullwhip Effect, Production \& Operations Management, Vol. 13 (2004), No. 2, pp. 150-160.

16. Y. Lu, Y. Tang, X. Tang, Study on the Complexity of the Bullwhip Effect, Journal of Electronic Science \& Technology of China, Vol.2 (2004), No.3, pp. 86-91.

17. D. Helbing, S. Lämmer, Supply and production networks: from the bullwhip effect to business cycles, in: D. Armbruster, A. S. Mikhailov, K. Kaneko (eds.), Networks of Interacting Machines: Production Organization in Complex Industrial Systems and Biological Cells, World Scientific, Singapore, 2005, pp. 33-66.

18. D. Makajić-Nikolić, B. Panić, M. Vujošević, Bullwhip Effect and Supply Chain Modelling and Analysis Using CPN Tools, in: K. Jensen (ed.): Proceedings of the Fifth Workshop and Tutorial on Practical Use of Coloured Petri Nets and the CPN Tools, Aarhus, 2004, pp. 219-234.

19. Ch. Carlsson, R.Fullér, A Fuzzy Approach to Taming the Bullwhip Effect, in: H.-J. Zimmermann et al. (eds.), Advances in Computational Intelligence and Learning: Methods and Applications, Kluwer 2002, pp. 247-262. 
20. I. Dhahri, H. Chabchoub, A Nonlinear Goal Programming Models Quantifying the Bullwhip Effect in Supply Chain Based on ARIMA Parameters, Proceedings of MOPGP'04, Hammamet, 2004.

21. T. Kelepouris, P. Miliotis, K. Pramatari, The impact of replenishment parameters and information sharing on the bullwhip effect: A computational approach, Athens University, Eltrun Working Paper Series, WP 2006-011, 2006.

22. M. Jakšic, B. Rusjan, Analysis of the bullwhip effect in supply chains using the transfer function method, Working Paper, Department of Management and Organisation, Faculty of Economics, University of Ljubljana, 2005.

23. Y. Merkuryev, J. Petuhova, R. Van Landeghem, S. Vansteenkiste, Simulation-based analysis of the bullwhip effect under different information sharing strategies, Proceedings of the $14^{\text {th }}$ European Simulation Symposium: Simulation in Industry - Modeling, Simulation and Optimization, A. Verbraeck, W. Krug (eds.), Dresden 2003, pp. 294-299.

24. J.-H. Thun, J.-P. Mertens, Simulating the impact of reverse logistics on the bullwhip effect in closed-loop-supply chains using system dynamics, Procedings of EurOMA 2006: Moving Up the Value Chain, Vol.1, Glasgow, 2006, pp. 265-274.

25. K. Donohue, R. Croson, Behavioral causes of the bullwhip effect and the observed value of inventory information, Management Science, Vol. 52 (2006), No. 3, pp. 323336.

26. R. Croson, K. Donohue, Upstream versus downstream information impact on the bullwhip effect, System Dynamics Review, Vol. 21 (2005), No. 3, pp.249-260.

27. Y. Wu, E. Katok, System-wide training and communication, the impact of learning on the Bullwhip Effect: An experimental study, Working Paper, Smeal College of Business, Penn State University, 2005.

28. N.H. Lurie, J.M. Swaminatham, The Role of Demand Information and Incentives in a Two-Stage Supply Chain, Working Paper, 2006.

29. J. Nienhaus, A. Ziegenbein, P. Schoensleben, How human behaviour amplifies the bullwhip effect. A study based on the beer distribution game online, Production Planning \& Control, Vol. 17 (2006), No. 6, pp. 547-557.

30. G. Ruël, D. P. van Donk, T. van der Vaart, The beer game revisited: Relating risktaking behaviour and bullwhip effect, Procedings of EurOMA 2006: Moving Up the Value Chain, Vol.1, Glasgow, 2006, pp. 403-412.

31. O.A. Carranza Torres, F.A. Villegas Morán (editors), The Bullwhip Effect in Supply Chains, Palgrave - MacMillan, 2006.

32. H. Peck, Reconciling supply chain vulnerability, risk and supply chain management, International Journal of Logistics: Research and Applications, Vol. 9 (2006), No. 2, pp. 127-142.

33. M. Christopher, H. Peck, Building the Resilient Supply Chain, International Journal of Logistics Management, Vol. 15 (2004), No. 2, pp. 1-14. 